\title{
Promotion of the lipase-catalyzed hydrolysis of conjugated linoleic acid I-menthyl ester by addition of an organic solvent
}

\author{
Takashi Kobayashi $^{1 *}$, Toshihiro Nagao ${ }^{2}$, Yomi Watanabe ${ }^{2}$ and Yuji Shimada ${ }^{3}$
}

\begin{abstract}
Conjugated linoleic acid I-menthyl ester was hydrolyzed in water by the lipase from Candida rugosa with the addition of an organic solvent. The degree of hydrolysis (yield) greatly improved when a tertiary alcohol, such as t-butyl alcohol, was added. However, the addition of a less polar solvent, such as hexane, decreased the degree of hydrolysis, and some water-miscible solvents, such as acetone, caused inactivation of the lipase. With the addition of t-butyl alcohol, the reaction mixture formed a one- or two-phase system, and the mixing ratio of substrates and $t$-butyl alcohol determined the number of phases. Although the degree of hydrolysis at $10 \mathrm{~d}$ was higher in the one-phase system, the initial reaction rate was generally lower. Meanwhile, the reaction was much faster in the two-phase system while maintaining a moderate degree of hydrolysis.
\end{abstract}

Keywords: Conjugated linoleic acid, Ester, Hydrolysis, Lipase, Organic solvent

\section{Background}

Commercially available conjugated linoleic acid (CLA) contains two structural isomers (9-cis,11-trans- and $10 t, 12 c$-CLA). It has been reported that each isomer has different physiological activities, such as an anti-cancer activity (Soel et al. 2007), decreasing the body fat content (Park et al. 1999), and suppressing the development of hypertension (Nagao et al. 2003a). To develop nutraceuticals containing the two CLA isomers of arbitrary amounts, a fractionation process of the CLA isomers is needed.

Some fractionation processes have been developed using the lipase-catalyzed selective esterification (Haas et al. 1999; Kobayashi et al. 2006; Nagao et al. 2003b). In these processes, lipases, such as from Candida rugosa, one of the most effective lipases for the esterification of CLA, were used, and some alcohols were used for the hydroxyl donors. l-Menthol is one these alcohols and very effective for the large-scale fractionation by selective esterification with CLA (Kobayashi et al. 2006). In this process, the alkali hydrolysis of CLA menthyl ester was needed to recover CLA as a free fatty acid. However, the hydrolysis requires

\footnotetext{
* Correspondence: tkoba@kais.kyoto-u.ac.jp

'Division of Food Science and Biotechnology, Graduate School of

Agriculture, Kyoto University, Sakyo-ku, Kyoto 606-8502, Japan

Full list of author information is available at the end of the article
}

heating under a strong alkaline condition, which may cause decomposition or isomerization of CLA. The lipasecatalyzed hydrolysis of CLA menthyl ester is considered to avoid these drawbacks. However, a degree of hydrolysis (yield) for CLA menthyl ester would be low in an oil/water two-phase system because the degree of the reverse reaction (esterification) is very high (ca. 80\%) at equilibrium (Kobayashi et al. 2007).

In general, the hydrolytic reaction system by lipases consists of two phases, i.e., water and oil phases in a neat reaction mixture. The water content in the oil phase is fixed in this case. However, addition of an organic solvent would promote the partition of water from the water phase to the oil phase, which results in changing the water content in the oil phase. To promote the hydrolysis, this change would be effective because the water content in the oil phase plays an important role in determining the degree of reaction in the two-phase system (Kobayashi et al. 2007). In this study, some organic solvents were added to the reaction system at various mixing ratios of the substrates and the solvent in order to evaluate the performance of the lipase-catalyzed hydrolysis of CLA menthyl ester. (c) 2012 Kobayashi et al.; licensee Springer. This is an Open Access article distributed under the terms of the Creative Commons Attribution License (http://creativecommons.org/licenses/by/2.0), which permits unrestricted use, distribution, and reproduction in any medium, provided the original work is properly cited. 


\section{Materials and methods Materials}

CLA in a free fatty acid form was a gift from The Nisshin OilliO Group, Ltd. (Tokyo, Japan), the fatty acid contents of which were $33 \% 9 c, 11 t$-CLA, 34\% 10t,12c-CLA, $4.9 \%$ other CLAs, $16 \%$ oleic acid, $6.4 \%$ palmitic acid, $2.7 \%$ stearic acid, and $2.2 \%$ other fatty acids. Lipase from Candida rugosa (Lipase-OF) was from Meito Sangyo (Aichi, Japan).

\section{Preparation of CLA menthyl ester}

Lipase from C. rugosa $\left(1.8 \times 10^{4} \mathrm{U} / \mathrm{g}\right.$-powdery enzyme) was used as an aqueous solution $\left(1.8 \times 10^{4} \mathrm{U} / \mathrm{mL}\right)$ in which $1 \mathrm{U}$ lipase was defined as the amount of lipase which liberated $1 \mu \mathrm{mol}$ free fatty acid/min during the hydrolysis of olive oil. Esterification of CLA was performed by stirring $100 \mathrm{~g}$ (0.36 mol) CLA, $55.8 \mathrm{~g}(0.36 \mathrm{~mol})$ l-menthol, and $8.67 \mathrm{~mL}$ lipase solution at $500 \mathrm{rpm}$ and $30^{\circ} \mathrm{C}$ for $7 \mathrm{~d}$ under a nitrogen atmosphere. After the reaction, the reaction mixture was separated into the oil and water phases by centrifugation. CLA menthyl ester and unreacted l-menthol were extracted with hexane after adding a $0.1 \mathrm{M}$ sodium hydroxide aqueous solution to the oil phase to remove any unreacted CLA (free fatty acid). The mixture of CLA menthyl ester and l-menthol was distilled under vacuum at $150^{\circ} \mathrm{C}$ and $500 \mathrm{~Pa}$ to obtain CLA menthyl ester as a distillation residue.

\section{Hydrolysis of CLA menthyl ester in the presence of an organic solvent}

CLA menthyl ester, organic solvent, and water at specific amounts were weighed into a screw-capped vial. In a typical procedure, $2 \mathrm{~g}$ CLA menthyl ester, $2 \mathrm{~g} t$-butyl alcohol and $1 \mathrm{~g}$ water were used. To the substrate mixture was added the powdery lipase from C. rugosa at $8.9 \times 10^{3}$ U/g-ester. The mixture was then stirred at $500 \mathrm{rpm}$ and $30^{\circ} \mathrm{C}$ for $10 \mathrm{~d}$ under a nitrogen atmosphere. The organic solvents used in this reaction were $t$-butyl alcohol, $t$-amyl alcohol, diacetone alcohol, diethyl ether, diisopropyl ether, hexane, cyclohexane, acetone, 2-butanone, cyclohexanone, and acetonitrile. The reaction without any organic solvent was also tested as the control. At appropriate intervals, the reaction mixture (ca. $250 \mathrm{mg}$ ) was sampled and analyzed to estimate the initial reaction rate, water content in the oil phase, and degree of hydrolysis.

\section{Analysis}

The water content in the oil phase of the reaction mixture was measured by Karl-Fischer titration using a CA-07 moisture meter (Mitsubishi-Kagaku, Tokyo). The measurement was performed at least five times using an $c a .40 \mathrm{mg}$ oil phase in each measurement, and the median value was adopted as the water content.

The degree of hydrolysis was determined by gas chromatography (GC). Prior to applying a sample to the GC, the reaction mixture was diluted 10 times with hexane. The diluted sample was centrifuged at $9000 \times g$ for $2 \mathrm{~min}$ to separate it into the hexane and water phases. After removing the water phase, solvents in the hexane phase were removed under vacuum. Free fatty acids in the residual oil underwent methylation as follows (Kobayashi et al. 2011): Ten milligrams of the oil was dissolved in $1 \mathrm{~mL}$ toluene/ methanol $(3: 2, \mathrm{v} / \mathrm{v})$. The solution was mixed well with a $25 \mu \mathrm{L}$ (trimethylsilyl)-diazomethane diethyl ether solution (2 M), and the mixture was stored for $10 \mathrm{~min}$ at room temperature. After methylation, the mixture was applied to a $6890 \mathrm{~N}$ GC (Agilent Technologies, CA, USA) connected to a DB-23 column (0.25 mm I.D. $\times 30 \mathrm{~m}$; Agilent). The column temperature was raised as follows: 150 to $200^{\circ} \mathrm{C}$, $10^{\circ} \mathrm{C} / \mathrm{min} ; 200$ to $210^{\circ} \mathrm{C}, 2^{\circ} \mathrm{C} / \mathrm{min} ; 210$ to $230^{\circ} \mathrm{C}, 15^{\circ} \mathrm{C} / \mathrm{min}$; kept at $230^{\circ} \mathrm{C}$ for $10 \mathrm{~min}$.

\section{Results and discussion}

Effect of the type of organic solvent on the hydrolysis Various kinds of organic solvents including hydrocarbons, ketones, tertiary alcohols, acetonitrile, and ethers were tested in order to evaluate the solvent effect on the hydrolysis of CLA menthyl ester. The reaction mixture consisted of two phases (oil/water) during the reaction for all cases when the reaction was performed using $2 \mathrm{~g}$ CLA menthyl ester, $2 \mathrm{~g}$ organic solvent, $1 \mathrm{~g}$ water, and $1.8 \times 10^{4} \mathrm{U}$ lipase. Table 1 shows the degree of hydrolysis at $1 \mathrm{~d}$. Organic solvents having a tertiary hydroxyl group ( $t$-butyl alcohol, $t$-amyl alcohol, and diacetone alcohol) greatly promoted the hydrolysis. Especially, when $t$-butyl alcohol or $t$-amyl alcohol, which was one of the water-miscible solvents, was used, the degree of hydrolysis at $1 \mathrm{~d}$ reached ca. $30 \%$. Meanwhile, when a relatively less polar solvent, such as diisopropyl ether, hydrocarbons, or cyclohexanone, was

Table 1 Effect of the type of an organic solvent on the degree of hydrolysis at $1 \mathrm{~d}$

\begin{tabular}{lc}
\hline Solvent & Degree of hydrolysis (\%) \\
\hline Control & $14.0 \pm 1.5$ \\
$t$-Butyl alcohol & $32.2 \pm 2.0$ \\
$t$-Amyl alcohol & $31.5 \pm 3.0$ \\
Diacetone alcohol & $20.5 \pm 2.5$ \\
Hexane & $9.2 \pm 2.2$ \\
Cyclohexane & $6.3 \pm 1.1$ \\
Cyclohexanone & $6.1 \pm 1.5$ \\
Acetone & $0.6 \pm 0.1$ \\
2-Butanone & $1.0 \pm 0.2$ \\
Diisopropyl ether & $7.5 \pm 1.0$ \\
Diethyl ether & $0.7 \pm 0.1$ \\
Acetonitrile & $0.7 \pm 0.2$
\end{tabular}

The reaction was performed in triplicate by mixing $2 \mathrm{~g}$ CLA menthyl ester, $2 \mathrm{~g}$ organic solvent, $1 \mathrm{~g}$ water, and $1.8 \times 10^{4} \mathrm{U}$ lipase at $30^{\circ} \mathrm{C}$ for $1 \mathrm{~d}$. 
used, the degree of hydrolysis was lower than that of the control $(<10 \%)$. One of the reasons may be as follows: The lipase-catalyzed hydrolysis occurs at the interface of the oil/ water phases, and the reaction behavior is greatly affected by the water content in the oil phase (Kobayashi et al. 2007). Although water activity is the most appropriate for evaluating the degree of hydrolysis in these systems, it is very difficult to determine all the reactant activities, including water activity, in a multi-component system. Therefore, we used the water content in the following study. Because many of these less polar solvents are only slightly miscible with water, these solvents lower the water content in the oil phase, resulting in the lower degree of hydrolysis. When diethyl ether, acetone, 2-butanone, and acetonitrile, which are water-miscible or miscible with water to a certain degree, were used, the hydrolysis only slightly proceeded. The low degree of hydrolysis may be due to the inactivation of the lipase by an organic solvent.

These results indicate that lipase from C. rugosa is not completely inactivated in a tertiary alcohol. On the other hand, other water miscible organic solvents, such as acetone and acetonitrile, readily inactivate the lipase. These facts contrast the fact that lipase from Candida antarctica (fraction B) shows a high catalytic activity not only in $t$-butyl alcohol, but also in acetone and acetonitrile (Kobayashi et al. 2010; Zhu et al. 2012). Based on these results, $t$-butyl alcohol was used for the following studies.

\section{State of the reaction mixture}

Because $t$-butyl alcohol is a water-miscible solvent and also miscible with CLA menthyl ester, the addition of $t$-butyl alcohol greatly changes the state of the reaction mixture which consists of two phases, i.e., aqueous and oil phases. When a small amount of $t$-butyl alcohol is added to the mixture, water and CLA menthyl ester are partitioned into the oil and aqueous phases, respectively. Meanwhile, the mixture will become one phase when more $t$-butyl alcohol is added. Therefore, the initial ratios of $t$-butyl alcohol, CLA menthyl ester and water were changed, and effects of the ratio on the hydrolysis were discussed from the viewpoint of the state of the reaction mixture, the initial reaction rate, and the degree of hydrolysis.

Hydrolysis was performed by changing the mixing ratio of CLA menthyl ester (1-2 g), $t$-butyl alcohol (0-30 g), and water (0.5-10 g). Typical time courses are shown in Figure 1. The reaction rate and degree (yield) of hydrolysis were greatly influenced by the addition of $t$-butyl alcohol. When a relatively small amount of $t$-butyl alcohol (25 wt\%) was added, the number of phases was two. The reaction in this composition proceeded very fast and reached equilibrium within $1 \mathrm{~d}$. On the other hand, when a large amount of $t$-butyl alcohol (83 wt\%) was added, the reaction mixture became one phase. The hydrolysis slowly proceeded and

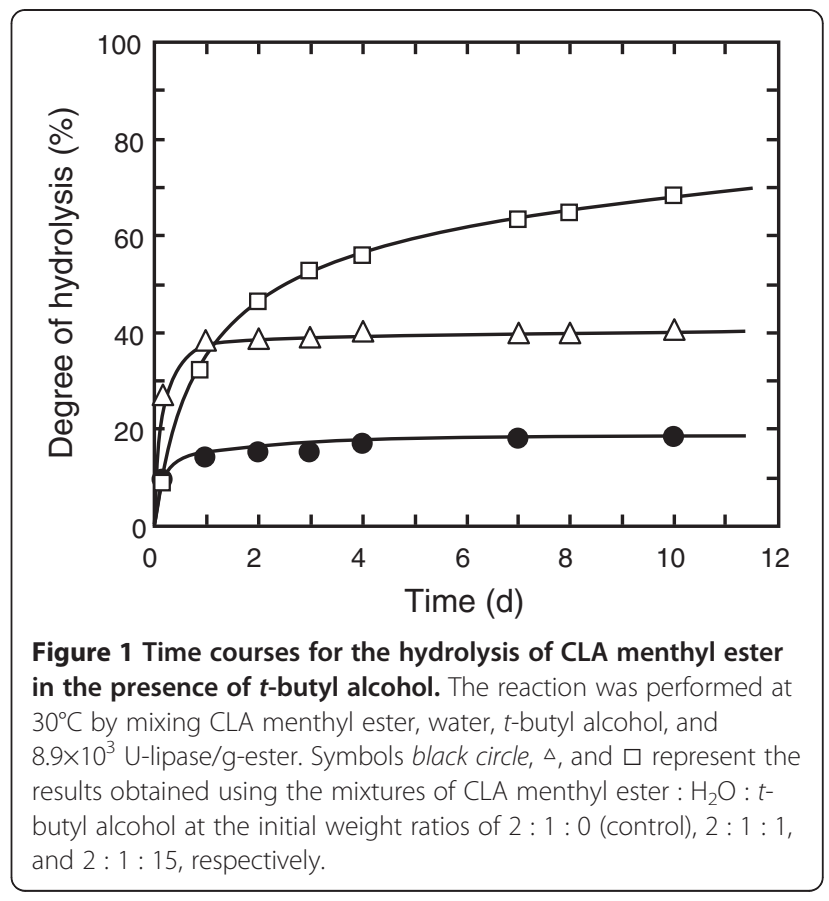

did not reach equilibrium within $10 \mathrm{~d}$. Although the reaction was slow, the degree of hydrolysis continued to increase during the reaction and reached $68 \%$ at $10 \mathrm{~d}$. These results indicate that the lipase from $C$. rugosa does not completely inactivate even at a high concentration of $t$-butyl alcohol, and that $t$-butyl alcohol positively affects the promotion of the hydrolysis. To shorten the reaction time, addition of much enzyme would be effective. Meanwhile, the control reaction almost reached equilibrium within $4 \mathrm{~d}$, and the degree of hydrolysis was lower $(18 \%$ at $10 \mathrm{~d}$ ) than that in the presence of $t$-butyl alcohol.

Figures 2 and 3 show ternary diagrams for the relative initial reaction rate and degree of hydrolysis at $10 \mathrm{~d}$, respectively, for various mixing ratios of CLA menthyl ester, water, and $t$-butyl alcohol. The mixing ratio greatly affected the initial reaction rate and the degree of hydrolysis in addition to the number of phases in the reaction mixture (one or two phases). When the content of $t$-butyl alcohol was less than $c a .60 \mathrm{wt} \%$, the reaction mixture consisted of two phases, but when a large amount of $t$-butyl alcohol was added, it became one phase. The effect of $t$-butyl alcohol is separately discussed for the one- and two-phase cases in the following sections.

\section{Hydrolysis in one-phase system}

In the one-phase system, the initial reaction rates were ca. 1-4 fold higher than that of the control in most cases (Figure 2). However, the significant addition of $t$-butyl alcohol tended to decrease the initial rate. Meanwhile, the degree of hydrolysis at $10 \mathrm{~d}$ greatly improved to $42-68 \%$ in all cases compared to that of the control as shown in 


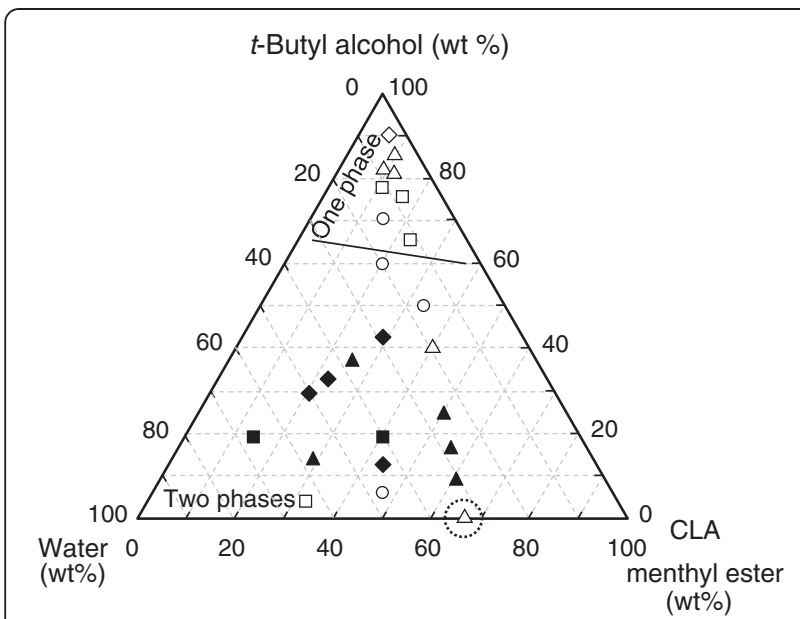

Figure 2 Dependence of the initial reaction rate on the mixing ratio of substrates and $t$-butyl alcohol. The initial rate without t-butyl alcohol (control) was $9.68 \mathrm{nmol} \mathrm{h}^{-1} \mathrm{U}^{-1}$ ), and its relative rate was regarded as 1.0. Symbols white diamond, $\Delta, \square, 0$, black diamond, black triangle, and black square represent the relative initial rate in the ranges of 0.30-0.99, 1.0-1.9, 2.0-2.9, 3.0-5.0, 7.0-7.9, 8.0-8.9, and 10-11,

respectively. The symbol inside the dotted circle represents the control. The reaction condition was the same as that in Fig. 1 except for the mixing ratio.

Figure 3, maybe due to the high concentration of water in the reaction mixture. However, the addition of a large amount of $t$-butyl alcohol lowers the substrate concentration. Therefore, performing the reaction under the onephase state is not practical.

There are some possibilities for the low reaction rate at the higher ratio of $t$-butyl alcohol: 1) Low substrate

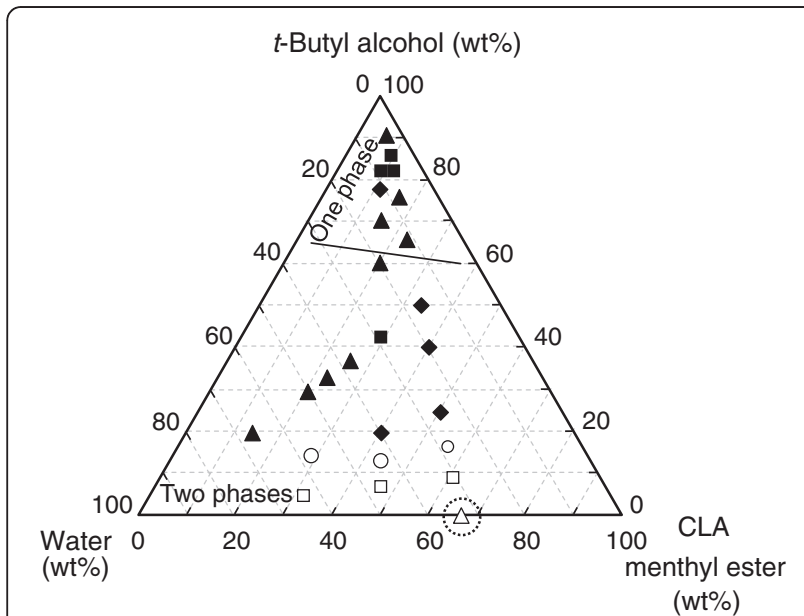

Figure 3 Dependence of the degree of hydrolysis on the mixing ratio of substrates and $\boldsymbol{t}$-butyl alcohol. Symbols $\Delta, \square, O$, black diamond, black triangle, and black square represent the degree of hydrolysis at $10 \mathrm{~d}$ in the ranges of $10-19 \%, 20-29 \%, 30-39 \%, 40-49 \%$, 50-59\%, and 60-70\%, respectively. The symbol inside the dotted circle represents the control. The reaction condition was the same as that in Figure 1 except for the mixing ratio. concentration is directly related to the low reaction rate. 2) Water-miscible organic solvents cause unfolding of the protein (Klyosov et al. 1975) or elimination of water molecules from an enzyme molecule that are essential to maintain its catalytic activity (Krishna et al. 2001). Therefore, lipase may be gradually inactivated by the significant addition of $t$-butyl alcohol. 3) A lipase molecule is generally adsorbed on the interface between the oil/water phases, and the interfacial activation produces the catalytic activity (Grochulski et al. 1993). In the one-phase system, however, there is no interface, and the behavior of the interfacial activation would be different from that in the typical two-phase system.

\section{Hydrolysis in two-phase system}

The initial reaction rates in the two-phase system were much improved for all cases compared to that of the control (Figure 2). Especially when the ratio of $t$-butyl alcohol was $9-50 \mathrm{wt} \%$, the reaction rates tended to greatly increase, and the maximum reaction rate reached $c a .10 .8$ times that of the control. These results would support the fact that the addition of a small amount of $t$-butyl alcohol activates the lipase from C. rugosa, and that the formation of the interface between the two phases is very important for the lipase to sufficiently exhibit its catalytic activity even in the presence of $t$-butyl alcohol.

The degree of hydrolysis is next discussed. The degrees of hydrolysis at $10 \mathrm{~d}$ were $24-61 \%$ in the presence of $t$-butyl alcohol and were higher than that of the control (Figure 3). In the two-phase system, the partition of water between the oil/water phases is an important factor affecting the reaction behavior. Water that is supplied to a catalytic center of a lipase molecule is transported through the oil phase

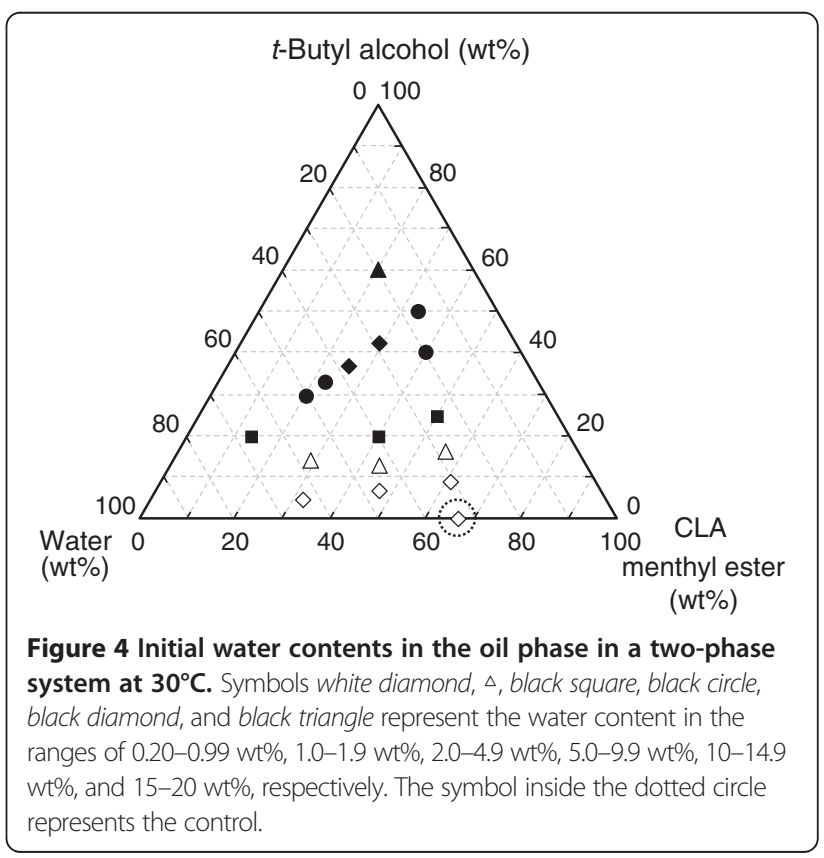


(Kobayashi et al. 2007). Therefore, it is favorable to increase the water content in the oil phase for improving the hydrolysis in the two-phase system. The initial water content was $0.2 \mathrm{wt} \%$ when $t$-butyl alcohol was not added, while it became $0.3-27 \mathrm{wt} \%$ with the addition of $t$-butyl alcohol (Figure 4). When the water content was greater than 2 wt $\%$, the degree of hydrolysis reached 40-61\%. In these cases, an unstable emulsion was formed, indicating that the formation of an emulsion would be an effective way to improve both the reaction rate and degree of hydrolysis. Based on these results, increasing the water content can be achieved by the addition of $t$-butyl alcohol to a certain amount, and its effectiveness has been revealed for significantly improving the hydrolysis of CLA menthyl ester. The same procedure may contribute to hydrolyze other esters in order to recover a free fatty acid and/or an alcohol.

\section{Conclusion}

In conclusion, the addition of an organic solvent greatly affected the degree of hydrolysis of CLA menthyl ester by the lipase from C. rugosa. When tertiary alcohols, such as $t$-butyl alcohol, were used, the degree of hydrolysis improved. The mixing ratio of substrates and $t$-butyl alcohol affected the number of phases, and the state of the phase much influenced the initial reaction rate and degree of hydrolysis. The initial reaction rate was generally lower in the one-phase system. In the two-phase system, the reaction was much faster, and a higher degree of hydrolysis could be achieved when the reaction mixture formed an emulsion. Therefore, to efficiently perform the hydrolysis, it is favorable to adopt the two-phase system in an emulsified form.

\section{Competing interests}

The authors declare that they have no competing interests.

\section{Authors' contributions}

TK performed the hydrolysis experiments and drafted the manuscript. TN and YW found the synthetic method of CLA esters and instructed TK in the synthesis of CLA menthyl ester. YS conceived the idea for fractionation of $\mathrm{CLA}$ isomers. All authors read and approved the final manuscript.

\section{Author details}

${ }^{1}$ Division of Food Science and Biotechnology, Graduate School of Agriculture, Kyoto University, Sakyo-ku, Kyoto 606-8502, Japan. ${ }^{2}$ Osaka Municipal Technical Research Institute, 1-6-50 Morinomiya, Joto-ku, Osaka 536-8553, Japan. ${ }^{3}$ Okamura Oil Mill Co., Ltd., 4-5, Kawaharacho, Kashiwara, Osaka 582-0004, Japan.

Received: 16 November 2012 Accepted: 11 December 2012 Published: 14 December 2012

\section{References}

Grochulski P, Li Y, Schrag JD, Bouthillier F, Smith P, Harrison D, Rubin B, Cygler M (1993) Insights into interfacial activation from an open structure of Candida rugosa lipase. J Biolog Chem 268:12843-12847

Haas MJ, Kramer KG, McNeill G, Scott K, Foglia TA, Sehat N, Fritsche J, Mossoba M, Yurawecz MP (1999) Lipase-catalyzed fractionation of conjugated linoleic acid isomers. Lipids 34:979-987
Klyosov AA, van Viet N, Berezin IV (1975) The reactions of a-chymotrypsin and related proteins with ester substrates in non-aqueous solvents. Eur J Biochem 59:3-7

Kobayashi T, Nagao T, Watanabe Y, Yamauchi-Sato Y, Negishi S, Shimada Y (2006) Enrichment of CLA isomers by selective esterification with I-menthol using Candida rugosa lipase. J Am Oil Chem Soc 83:93-99

Kobayashi T, Nagao T, Watanabe Y, Shimada Y (2007) Analysis of equilibrium state for synthesis of oleic acid I-menthyl ester in an oil-aqueous biphasic system with Candida rugosa lipase. Enz Microb Technol 40:1300-1304

Kobayashi T, Ehara T, Mizuoka T, Adachi S (2010) Efficient synthesis of 6-O-palmitoyl-1,2-O-isopropylidene-a-d-glucofuranose in an organic solvent system by lipase-catalyzed esterification. Biotechnol Lett 32:1679-1684

Kobayashi T, Nagao T, Watanabe Y, Shimada Y (2011) Direct GC analysis of the fatty acid compositions of conjugated linoleic acid and its I-menthyl esters. J Oleo Sci 60:445-448

Krishna SH, Divakar S, Prapulla SG, Karanth NG (2001) Enzymatic synthesis of isoamyl acetate using immobilized lipase from Rhizomucor miehei. J Biotechnol 87:193-201

Nagao K, Inoue N, Wang YM, Hirata J, Shimada Y, Nagao T, Matsui T, Yanagita T (2003a) The 10trans,12cis isomer of conjugated linoleic acid suppresses the development of hypertension in Otsuka long-evans Tokushima fatty rats. Biochem Biophys Res Commun 306:134-138

Nagao T, Yamauchi-Sato Y, Sugihara A, Iwata T, Nagao K, Yanagita T, Adchi S, Shimada $Y$ (2003b) Purification of conjugated linoleic acid isomers through a process including lipase-catalyzed selective esterification. Biosci Biotechnol Biochem 67:1429-1433

Park Y, Albright KJ, Storkson JM, Liu W, Pariza MW (1999) Evidence that the trans10, cis-12 isomer of conjugated linoleic acid induces body composition changes in mice. Lipids 34:235-241

Soel SM, Choi OS, Bang MH, Park JHY, Kim WK (2007) Influence of conjugated linoleic acid isomers on the metastasis of colon cancer cells in vitro and in vivo. J Nutri Biochem 18:650-657

Zhu G, Yao R, Zhu H, Wang H (2012) Novel and highly effective chemoenzymatic synthesis of (2R)-2-[4-(4-cyano-2-fluorophenoxy)phenoxy] butylpropanoate based on lipase mediated transesterification. Biotechnol Lett 34:709-715

doi:10.1186/2193-1801-1-67

Cite this article as: Kobayashi et al:: Promotion of the lipase-catalyzed hydrolysis of conjugated linoleic acid I-menthyl ester by addition of an organic solvent. SpringerPlus 2012 1:67.

\section{Submit your manuscript to a SpringerOpen ${ }^{\odot}$ journal and benefit from:}

- Convenient online submission

- Rigorous peer review

- Immediate publication on acceptance

- Open access: articles freely available online

- High visibility within the field

- Retaining the copyright to your article

Submit your next manuscript at $>$ springeropen.com 